Vol 10, Issue 10, 2017

\title{
AN OVERVIEW OF TRANSDERMAL DELIVERY SYSTEM
}

\author{
RESHMI JAYAPRAKASH, JAHNARA HAMEED, ANUPRIYA*
}

Department of Pharmaceutics, Amrita School of Pharmacy, Amrita Vishwa Vidyapeetham University, Amrita University, AIMS Healthcare Campus, Ponekkara P.O., Kochi, Kerala, India. Email: anupriya@aims.amrita.edu

Received: 13 May 2017, Revised and Accepted: 01 July 2017

ABSTRACT

Recently, most widely using conventional dosage form such as tablet, capsules, and injections but due to some case we are preferable to choose transdermal drug delivery system (TDDS) because conventional oral dosage form undergo first pass metabolism. In TDDS, skin is the effective medium for the penetration of drug into systemic circulation. This system required very low dose for the effective result or action. One of the major disadvantages of TDDS is penetration rate is very low through the stratum corneum. Nowadays, different types of skin penetration enhancement techniques are used for increasing the penetration. These types of techniques can be also increase the bioavailability. The patients have more preferable to choose this type of drug delivery system because it has more advantages than conventional dosage form. This article is discuses about the anatomy and physiology of skin and its drug penetration capacity, polymers used in transdermal drug delivery and different types of TDDS.

Keywords: Transdermal drug delivery, Skin, Polymers, Enhancement techniques.

(c) 2017 The Authors. Published by Innovare Academic Sciences Pvt Ltd. This is an open access article under the CC BY license (http://creativecommons. org/licenses/by/4. 0/) DOI: http://dx.doi.org/10.22159/ajpcr.2017.v10i10.19909

\section{INTRODUCTION}

Transdermal drug delivery system (TDDS) means TDDS. It is also known as patches. The first transdermal patches were approved by food and drug administration in 1981. Now-a-days this route is more popular and easy method for the application of drug to patient and also increases the therapeutic benefits to patient. This is the more successful delivery method for releasing of drug into the body. The system also more popular in pharmaceutical industry. It is very effective and produces sustained release to the body [1]. At present, different transdermal drugs are used for various disease such as hyoscin for motion sickness, nitroglycerine, and clonidine used for cardiovascular disease and fentanyl used for chronic pain. This system having several advantages and disadvantages are given below in Table 1.

\section{ANATOMY AND PHYSIOLOGY OF SKIN [5-7]}

Transdermal delivery mainly depends on the skin nature. Skin is the main route of administration of drug to body. Skin is the largest organ in the body. It provides microbial protection and produces sense. Mainly human body consists of three different types of skin layers (Fig. 1); these layers are responsible for the drug delivery to body.

1. Epidermis $(20-89 \mu \mathrm{m})$

2. Dermis $(0.3-3 \mathrm{~mm})$

3. Hypodermis.

\section{Epidermis}

The striated, vascular, and cellular epidermis are a multiple layered. This layer is occupying in different regions of the body with different thickness (Table 2). It consists of two types of epidermal layer.

- Stratum corneum: It is the outermost layer of the skin. This layer is also known as honey layer. In this region having 10-25 layers of keratinized dead cells, they called as corneocyes. This layer is the principle barrier for the penetration of drug, and also lipids are aligned in multiple bilayers. It prevents the excess loss of water from body and also permits lipid soluble topical agents.

- Viable epidermis: This layer is located on the beneath of the stratum corneum. It comprises of different layers in this region such as stratum granulosum, stratum lucidum, stratum spinosum, and stratum basal (Fig. 2).

\section{Dermis}

This layer is made up of a matrix of connective tissues such as lymph, nerves, and blood vessels. This layer provides oxygen to skin and also eliminate the waste product and toxins. Sweat glands and hair follicles are present in this region.

\section{Hypodermis}

It comprises subcutaneous fat tissue; it supports the dermis and epidermis. It is the deeper layer. This layer helps to provide mechanical protection support the nutrients and also it regulates the temperature.

\section{PENETRATION OF DRUG THROUGH SKIN}

In skin drug molecules are penetrate directly to the stratum corneum, this is achieved by mainly through three pathways such as hair follicles, sweat duct, and sebaceous gland (Fig. 3). In stratum corneum having lot of water it act as plasticizers; they are avoid the cracking of stratum corneum. The drug contains any hydrophilic chemicals it diffuses or passes through the aqueous membrane similarly lipophilic chemicals it diffuse through lipoid membrane [8]. This type of molecular transport of drug through barrier is determined by fluxes. At a given period of time no. of molecules pass through specific area of cross section is known as flux. Flux is determined by using an equation 1.

$\mathrm{J}=\mathrm{m} / \mathrm{At}$

J=Flux,

$\mathrm{m}=$ Mass of compound,

$A=$ Area of cross section $\mathrm{t}=$ Time.

The molecules are migrating through the barrier; this migration is happen because of external force applied on individual solute molecule [9]. Penetration of drug through outer membrane of stratum corneum obeys Fick's first law. Fick's first law is state that flux is directly proportional to concentration gradient. Fick's first law determined using an equation $2[10,11]$.

$\mathrm{dm} / \mathrm{dt}=-\mathrm{DS}(\mathrm{dC} / \mathrm{dx})$ 
Table 1: Advantages and disadvantages of TDDS

\section{Advantages of TDDS [2,3]}

Reduce the peak plasma levels of drug this leading to decrease side effect Reduce the fluctuation in plasma levels of drugs

Avoid $1^{\text {st }}$ pass metabolism of drug

It is a painless treatment

Enhancement of patient compliance

Reduction of dosing frequency

Easy elimination of drug delivery in case of toxicity

TDDS: Transdermal drug delivery system

Table 2: Thickness of different skin region

\begin{tabular}{ll}
\hline Skin region & Thickness $(\boldsymbol{\mu m})$ \\
\hline Palm & 400 \\
Forehead & 13 \\
Back & 10 \\
Abdomen & 15 \\
Forearm & 16 \\
Scrotum & 05 \\
\hline
\end{tabular}

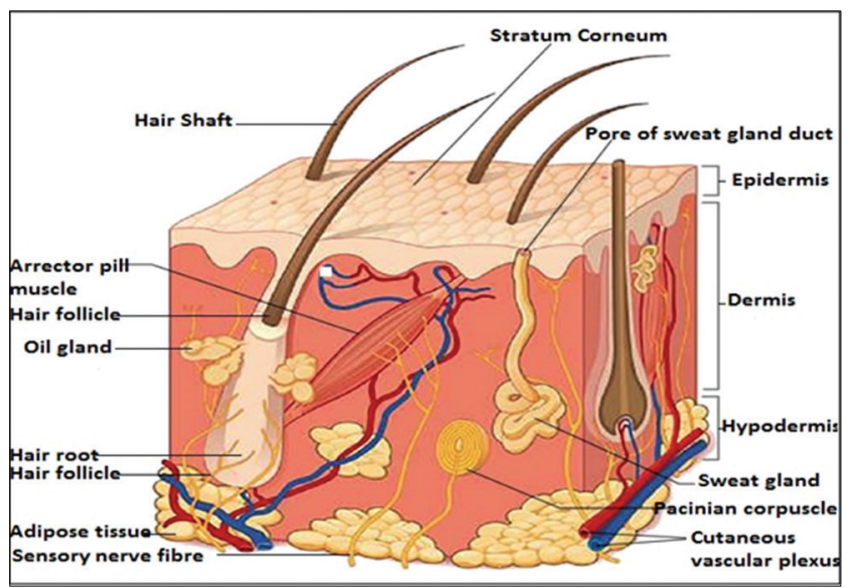

Fig. 1: Normal skin structure

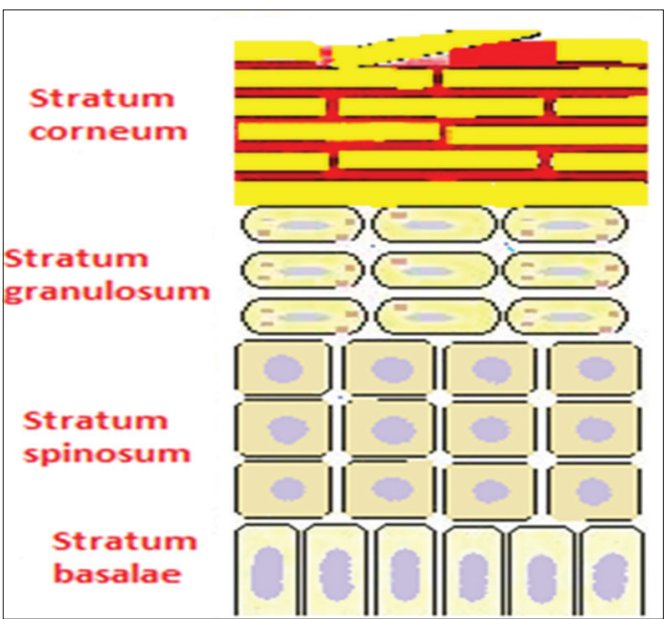

Fig. 2: Different layers of epidermis

$\mathrm{dm}=$ Change in mass of material, $\mathrm{g}$,

$\mathrm{dt}=$ Change in time, sec,

$\mathrm{D}=$ Diffusion coefficient, $\mathrm{cm}^{2} / \mathrm{sec}$

$\mathrm{S}=$ Barrier surface area, $\mathrm{cm}^{2}$,

$\mathrm{dC}=$ Change in concentration of material, $\mathrm{g} / \mathrm{cm}^{3}$.
Disadvantages of TDDS [4]

Drugs having very low or high partition coefficient fail to reach systemic circulation

Patients having higher molecular weight fail to penetrate the stratum corneum

High melting of drug due to low solubility of both water and fat

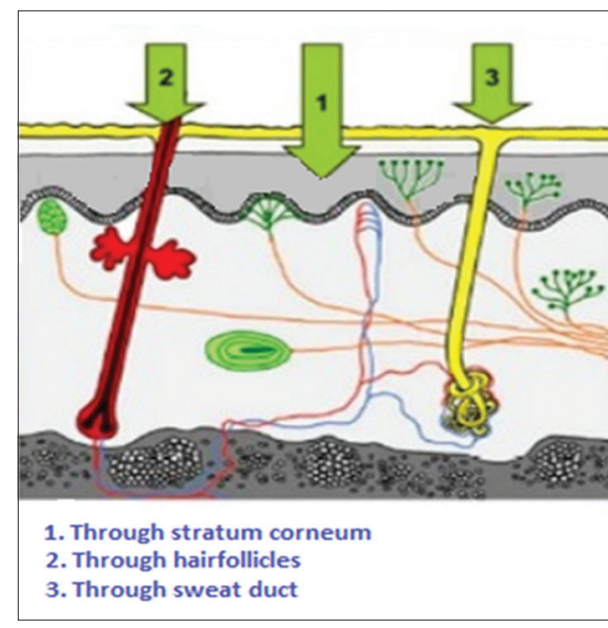

Fig. 3: Drug penetration pathway

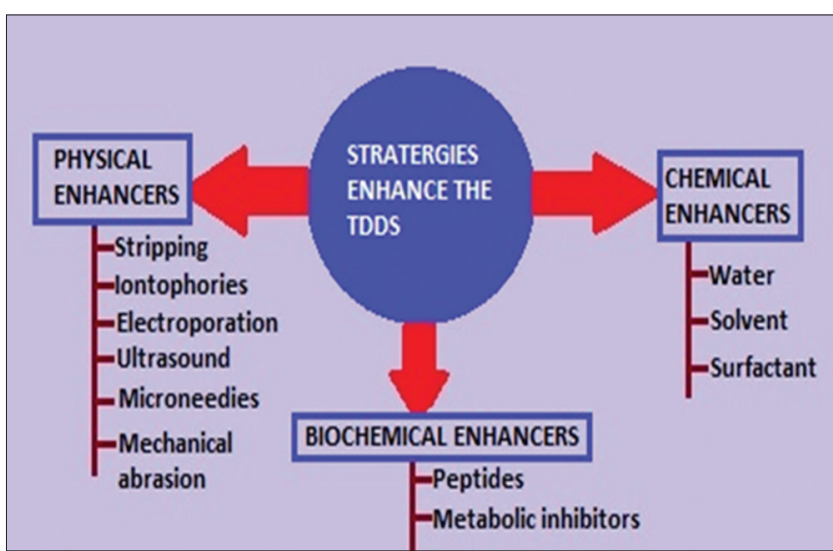

Fig. 4: Enhancement strategies of TDDS

Three strategies are used for enhance TDDS (Fig. 4). They are chemical, physical, and biochemical enhancement. When a compound is bind or interact with stratum corneum contain lipoidal membrane there by increase the permeability is known as chemical enhancement $[12,13]$. Biochemical enhancement directly increases the permeability of stratum corneum lipid membrane and also indirectly affects the skin permeability through change in the lipid metabolism [14]. Physical enhancement increases the drug delivery using some devices such as stripping, iontophoresis, electroporation, ultrasound, microneedles, and mechanical abrasion $[15,16]$.

\section{TYPES OF TDDS $[2,17]$}

TDDS classified into three types

1. Reservoir system

2. Matrix system

3. Microresevior system. 


\section{Reservoir system}

In this system, drug reservoir can aligned between backing layer and rate controlling membrane. Drug may be in the form of suspension, gel or solution. These drugs are dispersed on the solid polymeric matrix (Fig. 5).

\section{Matrix system}

The matrix system classified into two types of systems (Fig. 6):

- Drug adhesive system: The drug reservoir is formed by the dispersion of drug to an adhesive polymer; then, it spread on the medicated adhesive polymer or melt on backing layer.

- Matrix dispersion system: The drugs are homogeneously dispersed o the lipophilic or hydrophilic polymer matrix. The drugs having polymer is fitted on a particular base plate. From a drug impermeable backing layer, it self it spread to form a strip of adhesive rim instead of applying the adhesive or phase of drug reservoir.

\section{Microreservior system}

This system is the combination of matrix dispersion and reservoir. First drug is dissolved in an aqueous solution of water-soluble polymer, then it is dispersed in lipophilic polymers to form microscopic spheres of drug reservoir (Fig. 7).

\section{COMPONENTS OF TDDS}

- Release liner: This liner should be chemically inert. This liner provides intimate contact to skin. A protective line is covering the patch during the storage condition. It is removed before the application of patch to the skin.

- Backing layer: This layer is protecting the patch from the external environment. It should be a penetration enhancers and it is made up of different type's polymers such as polyethylene, polyolefin, and polyester film [18].

- Membrane: This layer is cover or seals the backing to forming a pocket. Drug matrix is occupy in this pocket.

- Enhancers and excipients: Different types of enhancers and excipients are increasing the skin permeability, e.g.,: Propylene glycol, isopropyl myristate, and n-methyl-pyrrolidone [19-21]

- Pressure sensitive adhesive: This is bind to the skin due to the intermolecular and intraatomic force and it achieves good contact [22].

\section{POLYMERS}

Polymers are the backbone of TDDS. Polymers play a key role in human body. Polymers are classified into three types: Natural, semisynthetic, and synthetic (Fig. 8). Selection of polymer is very important for the development of product. And also polymers having several ideal properties, these properties are playing a major role in this system. Ideal properties such as $[23,24]$ :

- It should be chemically inert.

- It should be nontoxic.

- It doesn't decompose during storage.

- Diffusion of drug is depended on the chemical, physical character of polymer and also depend molecular weight of polymer.

Main uses of natural polymer are it is biodegradable, good cytocompatibility. Synthetic polymers are mainly used for different purposes such as film (polyethylene), rope and automotive (polypropylene), insulation and packaging (polystyrene), cable wire insulator (polyvinyl chloride), and aqueous soluble thickening agent (polyvinyl alcohol) [25,26]. Different types of polymers are used based on the type of actions. The polymers and drugs are arranged like a "sand witch" model in the TDDS. Polymers are preventing the leakage of drugs and provide a sustained release into the body. The polymers are select depend on the $\mathrm{pH}$ of particular region of body. The polymers are swells and release the drug at only that region of $\mathrm{pH}$. In TDDS using different polymers given below in Table $3[27,28]$.

\section{ROLE OF ADHESION IN DRUG DELIVERY}

In TDDS, main principle is it selectively adhere the skin and provide drug release. Drug delivery is varied in age and gender function.

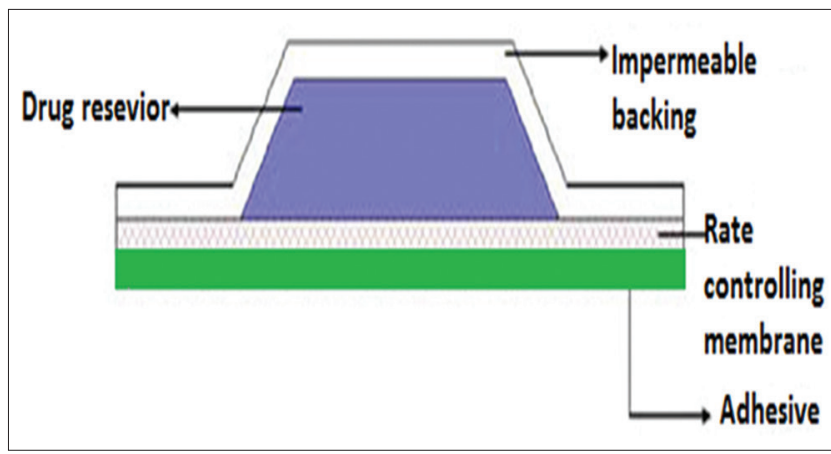

Fig. 5: Reservoir system

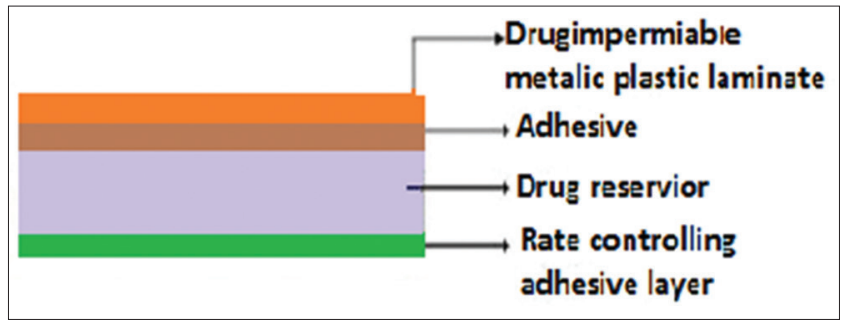

Fig. 6: Matrix system

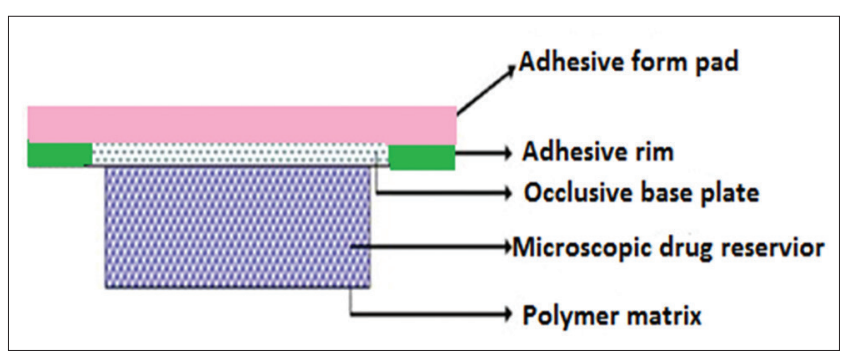

Fig. 7: Microreservior system

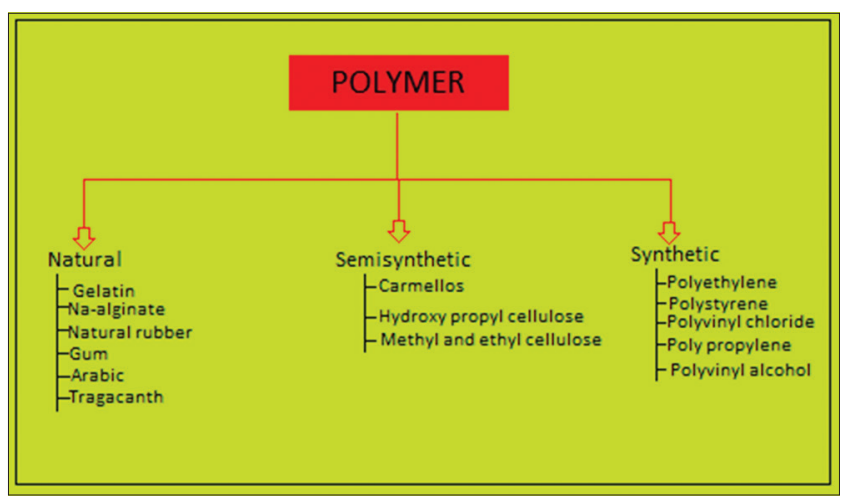

Fig. 8: Classification of polymer

Because in this system drug release is through the skin and also younger and older patient having different skin nature. Younger skin is greater dehydrated while aged skin has less moisture content so younger skin have more elastic than aged skin so we carefully select the adhering material for the drug release. This type of condition role of adhesion is very important [29]. Here, drug absorption based on the drug partition between TDDS and skin. Good permeation and action is depending on the proper adhesion of patch. After the application of patch the adhesion covers the particular effective area, that area only provides greater action [30]. And also so many factors are affecting the drug absorption such as thickness of skin, skin temperature, blood flow, no. of hair follicles, skin cleansing, sweat gland function, $\mathrm{pH}$ of skin 
Table 3: Types of polymers used in TDDS

\begin{tabular}{ll}
\hline Types & Polymers \\
\hline Matrix formers & Poly ethylene glycol \\
& Ethyl cellulose and polyvinylpyrrolidone \\
& Hydroxy methyl cellulose \\
& Organo gels \\
Rate controlling & Silicon rubber \\
& Polyurethane \\
Pressure sensitive & Silicon \\
adhesives & Polyisobutylene \\
& Polyacrylates \\
Thermoplastic hot & Compounded \\
melt pressure sensitive & Ethylene vinyl acetate co-polymer \\
adhesives & Paraffin wax \\
& Low density polypropylene \\
& Styrene-butadiene co-polymer \\
& Ethylene-ethacrylate co-polymer \\
& Uncompounded \\
& Polyesters \\
& Polyamides \\
& Polyurethanes \\
& Polyurethane \\
& PVC \\
& PE \\
& EVA \\
\hline
\end{tabular}

PVC: Polyvenylchloride, PE: Polyethelene, EVA: Ethylenevinyl acetate

surface, and body temperature [31-33]. After the application of patch, it warms the sin temperature that lead to increase the flow of drug to skin. During the gradually increasing of skin temperature swells the polymer and sustained release of drug to stratum corneum [34]

\section{FACTORS AFFECTING DRUG PENETRATION}

Two types of factors affect the drug penetration such as biological and physiochemical factors these factors are listed below [35-38]:

- Biological factors

- Skin age

- Skin condition

- Species difference

- Blood supply

- Skin metabolism

- Regional skin site.

- Physiochemical factors

- Temperature and $\mathrm{pH}$

- Skin hydration

- Diffusion coefficient

- Drug content

- Molecular size and shape

- Partition coefficient.

\section{CONCLUSION}

TDDS more convenient method for the delivery of drug to human body. This type of drug delivery patients can easy to handle. It provides a sustained release through the skin. Skin and patch adhesion is the important factor for the delivery of drug. Drug should have definite molecular weight about $<500$ Dalton (low molecular weight) and also lipophilicity and water solubility should be medium level. Otherwise, drug penetration and its therapeutic effect cannot reach the target site. During the delivery of drug, it provides a constant blood flow and also predetermined rate of drug release. The enhancement techniques such as iontophoresis using small voltage and electrophoresis using high voltage to passing the lipoid barrier and push the drug molecule into systemic circulation.

\section{REFERENCES}

1. Ritesh K, Anil P. Modified transdermal technology: Breaking the barriers of drug permeation via the skin. Trop J Pharm Res 2007;6(1):633-44.
2. Barry B. Transdermal drug delivery. In: Aulton EM, editor. Pharmaceutics: The Science of Dosage form Design. $2^{\text {nd }}$ ed. New York: Harcourt Publishers; 2002. p. 499.

3. Kumar P, Sankar C, Mishra B. Delivery of macromolecules through skin. Indian Pharm 2004;5(3):7-17.

4. Finnin CB. Transdermal drug delivery-what to expect in the near future. Bussiness Briefing: Pharm Tech. London: World Market Research Centre; 2003. p. 192-3.

5. Nikhil S, Geta A, Rana AC, Zulfiqar A, Dinesh K. A review: Transdermal drug delivery system: A Tool for novel drug delivery system. Int J Drug Dev Res 2011;3(3):70-84.

6. Tortora GJ, Bryan D. Principles of Anatomy and Physiology. 13 $3^{\text {th }}$ ed., Vol. 1. New York: J. Wiley; 2011. p. 154-61.

7. Vyas SP, Khar RK. Controlled Drug Delivery: Concepts and Advance. $1^{\text {st }}$ ed. New Delhi: Vallabh Prakashan; 2002. p. 411-77.

8. Heather AE. Transdermal drug delivery: Penetration enhancement techniques. Curr Drug Deliv 2005;2(1):23-33.

9. Birger B, Bente S, Carsten UN. Passive Diffusion of Drug Substance: The Concepts of Flux and Permeability. Available from: http://www. pharmpress.com/files/docs/molbiopharmaceutics.sample.pdf.

10. Subrahmanyam CV. Text book of Physical Pharmaceutics. New Delhi: Vallabh Prakashan; 2010. p. 110-26.

11. Rakesh R, Anoop KR. Formulation and optimization of nano-sized ethosomes for enhanced transdermal delivery of cromolyn sodium. J Pharm Bioallied Sci 2012;4(4):333-40.

12. Williams AC, Barry BW. Penetration enhancers. Adv Drug Deliv Rev 2004;56(5):603-18.

13. Murali S, Nair SC, Priya A. Drug delivery research: Current status and future prospects. Int J Pharm Sci Rev Res 2016;40(1):94-9.

14. Tsai JC, Guy RH, Thornfeldt CR, Gao WN, Feingold KR, Elias PM. Metabolic approaches to enhance transdermal drug delivery 1 . Effect of lipid synthesis inhibitors. J Pharm Sci 1996;85(6):643-8.

15. Arora A, Prausnitz MR, Mitragotri S. Micro-scale devices for transdermal drug delivery. Int J Pharm 2008;364(2):227-36.

16. Banga AK. Transdermal and Intradermal Delivery of Therapeutic Agents: Application of Physical Technology. Boca Raton, FL: RC Press; 2011

17. Wokovich AM, Prodduturi S, Doub WH, Hussain AS, Buhse LF. Transdermal drug delivery system (TDDS) adhesion as a critical safety, efficacy and quality attribute. Eur J Pharm Biopharm 2006;64(1):1-8.

18. Debjit B, Pusupoleti KR, Duraivel S, Sampath K. Recent approaches in transdermal drug delivery system. J Pharm Innov 2013;2(3):99-107.

19. Keith AD. Polymer matrix consideration for transdermal device. Drug Dev Ind Pharm 1983;9:602-25.

20. Cornwell PA, Barry BW. Sesquiterpene components of volatile oils as skin penetration enhancers for the hydrophilic permeant 5-fluorouracil. J Pharm Pharmacol 1994; 46: 261-269.

21. Qvist MH, Hoeck U, Kreilgaard B, Madsen F, Frokjaer S. Release of chemical permeation enhancers from drug-in-adhesive transdermal patches. Int J Pharm 2002;231(2):253-63.

22. Minghetti P, Cilurzo F, Montanari L. Evaluation of adhesive properties of patches based on acrylic matrices. Drug Dev Ind Pharm 1999;25(1):1-6.

23. Archana KG. Transdermal drug delivery system: Formulation aspects and evaluation. J Pharm Sci 2013;1(1):1-10.

24. Sugibayashi K, Morimoto Y. Polymers for transdermal drug delivery system. J Control Release 1994;29:177-85.

25. Arti K, Ajit KY, Sunil S, Henendra G, Haribansh NS, Anamika S, et al. Theoretical aspects of transdermal drug delivery system. Bull Pharm Res 2013;3(2):78-89.

26. Bromberg L. Cross-linked ploy (ethylene glycol) networks as reservoirs for protein delivery. J Appl Polym Sci 1996;59:459-66.

27. Sateesh K, Vinod N, Ramesh P. Polymer in transdermal drug delivery system. Pharm Technol 2002;26:62-80.

28. Repka MA, McGinity JW. Bioadhesive properties of hydroxypropylcellulose topical film produced by hot-melt extrusion. J Control Release 2001;70(3):341-51.

29. Gupta SK, Southam M, Gale R, Hwang SS. System functionality and physicochemical model of fentanyl transdermal system. J Pain Symptom Manage 1992;7 3 Suppl: S17-26.

30. Fauth C, Wiedersberg S, Neubert RH, Dittgen M. Adhesive backing foil interactions affecting the elasticity, adhesion strength of laminates, and how to interpret these properties of branded transdermal patches. Drug Dev Ind Pharm 2002;28(10):1251-9.

31. Ashburn MA, Ogden LL, Zhang J, Love G, Basta SV. The pharmacokinetics of transdermal fentanyl delivered with and without controlled heat. J Pain 2003:4(6):291-7. 
32. Harrison LL, Harari D. An evaluation of bioequivalence of two 7-day 17 beta-estradiol transdermal delivery systems by anatomical site. J Clin Pharmacol 2002;42(10):1134-41.

33. Larsen RH, Nielsen F, Sørensen JA, Nielsen JB. Dermal penetration of fentanyl: Inter-and intraindividual variations. Pharmacol Toxicol 2003;93:244-8.

34. Wick KA, Wick SM, Hawkinson RW, Holtzman JL. Adhesion-to-skin performance of a new transdermal nitroglycerin adhesive patch. Clin Ther 1989;11(5):417-24.

35. Finnin BC, Morgan TM. Transdermal penetration, application, limitation and potential. J Pharm Sci 1999;88(10):955-8.

36. Zhou Y. Fine element analysis of diffusional drug release from complex matrix system. J Control Release 1997;49(2-3):277-88.

37. Rajesh N, Siddaramaiah, Gowda DV, Somashekar CN. Formulation and evaluation of biopolymer based transdermal drug delivery. Int $\mathrm{J}$ Pharm Pharm Sci 2010;2(2):142-7.

38. Dey S, Malgope A. Preparation of carvedilol transdermal patch and the effect of propylene glycol on permeation. Int J Pharm Pharm Sci 2010;2 Suppl 1:137-43. 